\title{
Creative Meaning-Making through a Multimodal, Interdisciplinary Exploration: Lessons for Higher Education Curriculum Enhancement
}

\author{
Belinda Verster \\ Karen Collett \\ Carolien van den Berg
}

\begin{abstract}
Within the context of the neoliberal managerialism that is pervading higher education in South Africa, academia is driven by a stringent set of prescriptions. Teaching within this environment can constrain opportunities for creativity and lateral thinking by students and staff alike. Student protests in 2015 and 2016 provided a challenge and provocation to academics to think about the transformational nature of their curriculum design, content and pedagogy. This paper explores the collaboration between three senior academics as they engaged in a process of professional academic development. This experience opened up generative spaces for them to think in new and creative ways about their teaching and curriculum design. A collaborative autoethnographic methodology, informed by a social constructivist approach, was used to explore their experience. The authors trace their interactions with different mediums and each other as 'a continuous process of making and unmaking' (Jackson \& Mazzei 2013: 262). The lenses of Touch (Barad 2012), an Ethic of Care (Tronto 2013) and Slow Pedagogy (Bozalek 2017) were used to make meaning of their experiences. Key lessons they identified as enhancing their teaching were: 'space of (for) becoming', 'academic praxis', 'deconstructing and reconstructing entanglement', 'learning-by-modelling', and 'decolonising thinking and meaning-making'. This paper holds lessons that can inform curriculum development in higher education, especially in a
\end{abstract}


time when strong calls are mounting for 'disruptive shifts to revitalise higher education curricula' (Dhunpath \& Amin 2019: 1).

Keywords: multimodal pedagogy, interdisciplinary collaboration, creative meaning-making, professional academic development, curriculum enhancement

\section{Introduction}

This paper explores our collaborative experience as we journey toward transforming our teaching and learning through two professional academic development courses, as well as our ongoing engagement in a community of praxis (Burke 2018). It highlights key shifts we made in our thinking about our own teaching and learning practices, and provides extracts from lessons that can be used to address issues of transformation in the wake of student protests for decolonising the curriculum.

The position we represent in this paper is that of three female, senior academics from different disciplinary fields, namely urban planning, educational leadership and information systems, from two different higher education institutions in the Western Cape. We shared the need to collaboratively explore how we can transform our teaching and curriculum design and respond to the needs of our students and our disciplines by first expanding our own knowledge, skills and value sets through professional academic development (PAD).

Our need to revitalise and re-imagine our professional practice stems from the numerous shifts and pressures in the higher education landscape in South Africa that call for meaningful and 'responsible' pedagogy. Student protests in South African higher education institutions (HEIs), with their associated shifts of recurriculation, renewed focus on throughput rates (as a measure of academic quality) and changes in the power dynamics created pressure points that we attempt to start addressing through the writing of this paper.

The student protests bear testimony to the urgency for pedagogy and curricula to address issues of inequality, injustice and misrepresentation in higher education. Bozalek and Zembylas (2017: 64) argue that more theoretical and methodological tools are needed to 'envision and enact socially just pedagogies in higher education'. We find ourselves in a position where 
'the ground is in motion' (Jamal \& Gets 1995: 188), which challenges academics to question their curriculum content and delivery.

Heleta (2016: 2) argues that higher education institutions require fundamental epistemological change in the curriculum and continues to perpetuate epistemic violence through 'a curriculum which remains largely Eurocentric and continues to reinforce white and Western dominance and privilege while at the same time being full of stereotypes, prejudices and patronising views about Africa and its people'.

We argue in favour of a new way of thinking and being as academics, as the impetus for repositioning and rethinking our curriculum. Using a collaborative auto-ethnographic methodology informed by a social constructivist approach, we explore our collective experience in PAD courses and the journey of transforming our thinking. The different lenses of Touch (Barad 2012), an Ethic of Care (Tronto 2013) and Slow (Bozalek 2017) are applied to explore the constructive engagements across disciplinary boundaries to engage with the multiple insights of multiple fields. The paper concludes by exploring how 'space of (for) becoming', 'academic praxis', 'deconstructing entanglement', 'learning-by-modelling' and 'decolonising thinking', as revealed by our data analysis, can inform new ways of engaging with curriculum design, content and pedagogy in higher education.

\section{A Social Constructivist Orientation}

A social constructivist orientation informed the way in which we engaged with the processes of meaning-making towards our own professional academic development. This also informed the thinking of possibilities for transforming our curricular design, content and pedagogy.

A relational epistemology and ontology informed our understanding and interpretation of our experience. A relational epistemology acknowledges the fluid and multidimensionality of knowing and becoming, 'a continuous process of making and unmaking' (Jackson \& Mazzei 2013: 262) through engagement with each other and our environment. Meaning-making in our academic development process was enacted through what Deleuze and Guattari (1988) refer to as a rhizomatic assemblage of ceaselessly established non-linear and multi-layered connections.

Our engagement with and through PAD courses enabled us to think collectively about ways to attentively review and reimagine our curricula. 
Through this process of interacting with each other on the PAD courses and engaging with multimodal ways of learning, we experienced new ways of becoming and thinking about our world and work.

\section{An Interdisciplinary Community of Praxis}

We understand a community of praxis to mean a grouping (people) and a space (material) that assist in developing and enriching our teaching and learning praxis. Burke (2018: 19) describes this understanding as follows: 'A praxisbased, pedagogical methodology makes time and space for collaborative, reciprocal, critically reflexive and ethical ways of researching collectively across'. It is thus not merely a reflection on what and how we do things, but is also a way of enhancing our practice through critical engagement with theory and further enriching practices. We did this through a process of weekly face-to-face writing sessions, attending PAD courses as a group, and co-presenting at seminars and conferences.

Our community of praxis is defined by our professional lived experiences as three female, senior academics from two HEIs in Cape Town, in the Western Cape province of South Africa. We specialise in the professional disciplines of urban planning, educational leadership and information systems. This specific combination of areas of speciality has a profound impact on the nature of our interdisciplinary community by focusing on both the social-environmental as well as the techno-human interfaces. The combination of perspectives from the socio-environ-techno-human enriches our process of meaning-making by drawing on a diverse range of preknowledge, and thus vantage points of understanding.

It should be noted that, up to now, students have not been part of our community of praxis. Although we have introduced many of the practices we have learnt and developed in our teaching and learning strategies, we have not formally included students in the deeper conversations. We have now come to a point in our own professional academic development where we feel capable of opening up the conversation to allow 'multiple voices in the construction of truth(s)' (Gergen \& Gergen 1991: 80).

Gergen and Gergen (1991) refer to the concept of relational reflexivity as a critically important method of engaging within a community of praxis. The idea that the 'subjects become the participants' (Pedler 2012: 273) applies to this paper, where the site of the research is our community of praxis. 


\section{The Lenses of Touch, an Ethic of Care and Slow}

We applied the lenses of Touch (Barad 2012), a Political Ethic of Care (Tronto 2013) and Slow scholarship (Bozalek 2017) to the reading of our experiences. This enabled us to explore our pedagogy and find new ways to generate creative meaning. Our process of concept development unfolded over time, in what Schatzki (as cited in Kemmis et al. 2014: 33) describes as 'activity timespace, in which an activity unfolds in time, and in which objects in physical space are linked together and arranged by a particular activity'. We engaged with the concept of touch and how our journey enabled us to find new meaning and to explore being in touch through different mediums. Barad (2012: 208) posits that 'experimenting is about being in touch...touch moves and affects what it effects'. Our collaboration has enabled us to be in touch and this evoked responsibility and attentiveness to the emergency of new ideas (Barad 2012; Tronto 2013).

This responsibility for the other, as the other in our community of praxis, was strongly grounded in an Ethic of Care (Tronto 2013). We functioned as a community of praxis both during the PAD courses and when we met to work on our collaborative project. Tronto (2013) identifies five phases of care, each building upon the next. Phases of care include caring about; caring for; caregiving; care receiving and caring with. Being attentive and responsible for and with each other and our environment infused the way in which we made new meaning (Van den Berg, Verster \& Collett 2018). Bozalek and Zembylas (2017: 67) argue for a response-able pedagogy that pays attention to 'the engagement across differences and the way in which they happen are very important - this means the ability to apprehend'.

We believe that this cannot be explored without the addition of Slow, which requires an attentive and deepened engagement in our professional academic development (Collett et al. 2018). Slowness calls for calm, careful, receptive, still, intuitive, unhurried, patient and reflective quality over quantity. It is about making real and meaningful connections with people and places (Ulmer 2018). Part of the attraction to Slow learning and pedagogy lies in its ability to encourage 'time to plan, fail, retry, and reflect' (Shaw, Cole \& Russell 2013: 320).

We argue in favour of a multimodal approach using a range of mediums and ways of engaging (clay, books, sculpting, colour, nature and setting, human interaction and technology). Engaging through different mediums assisted us in slowing down the process of meaning-making. This 
was done through paying attention to the patterns of difference that emerged. Bozalek and Zembylas (2017: 65) provide the following elaboration on mattering: 'For Barad, matter is not just of the head but also of the heart and hands; it has to do with a scholarly engagement with care, social justice and seeing oneself as part of a world'.

These lenses highlight the notion of curriculum design, content and pedagogy as engaged processes of making and unmaking, which hold possibilities for empowerment and enrichment for both students and academics.

\section{Methodology}

A collaborative auto-ethnographic process was used to generate data to allow meaning to emerge through our analysis. Collaborative [auto] ethnography is defined by Chang, Ngunjiri and Hernandez (2013: 22) as a 'method in which researchers work in community to collect their autobiographical materials and to analyze and interpret their data collectively to gain a meaningful understanding of sociocultural phenomena reflected in their autobiographical data'.

It is a qualitative approach that positions self-enquiry at the centre (Chang et al. 2013). The authors give four considerations that define collaborative [auto] ethnography (CAE): self-focused, researcher-visible, context-conscious and critically dialogical.

It should be noted that, although we find resemblances with CAE, we are also confronted with differences to the approach advocated by Chang et al. (2013). We did not engage in this process of meaning-making as individuals, but as a collective, thus the self is not the focus anymore. The researcher is replaced by the community of praxis. For this reason, we use the [ ] to distinguish the [auto] from autoethnography.

We subscribe to Burke's (2018: 16) definition of a community of praxis. It resonates with our experience of meaning-making, which includes:

The bringing together of critical reflection and action - to ensure that those taken-for-granted meanings that unwittingly perpetuate inequalities are challenged and eradicated at both the individual and institutional levels. Through this cycle of praxis we are enabled to create more refined, sensitive and nuanced strategies for equity.

A further difference lies in our engagement with data, as we do not see data in 
its traditional configuration - as something that is captured and then analysed and interpreted. We continuously create data and make meaning from data. We do not consider data creation as something that is external to our community of praxis.

Table 1: The four collaborative [auto] ethnographic considerations, and our application of and divergence from them.

\begin{tabular}{|l|l|l|}
\hline $\begin{array}{l}\text { CAE Considera- } \\
\text { tions }\end{array}$ & $\begin{array}{l}\text { Key Text (Chang } \text { et } \\
\text { al. 2013) }\end{array}$ & $\begin{array}{l}\text { Application and } \\
\text { divergence }\end{array}$ \\
\hline Self-focused & $\begin{array}{l}\text { 'the researcher is } \\
\text { simultaneously the } \\
\text { instrument and the } \\
\text { data' }\end{array}$ & $\begin{array}{l}\text { The data sources we } \\
\text { interrogate are notes, } \\
\text { voice recordings and } \\
\text { artefacts we produced as } \\
\text { individuals and as a } \\
\text { collective. }\end{array}$ \\
\hline
\end{tabular}

\begin{tabular}{|l|l|l|}
\hline Researcher-visible & $\begin{array}{l}\text { 'the researcher turns } \\
\text { the lens inward to } \\
\text { make personal } \\
\text { thoughts and actions } \\
\text { visible and } \\
\text { transparent' }\end{array}$ & $\begin{array}{l}\text { We pick up on the } \\
\text { nuances of the process of } \\
\text { collaborative meaning- } \\
\text { making because of our } \\
\text { location as both } \\
\text { researchers and subjects } \\
\text { of the inquiry. }\end{array}$ \\
& $\begin{array}{l}\text { The frameworks we } \\
\text { subscribe to (Touch, } \\
\text { Ethic of Care and Slow) } \\
\text { sensitised us to these } \\
\text { traces and nuances. }\end{array}$ \\
\hline Context-conscious & $\begin{array}{l}\text { 'studying the self in } \\
\text { context' }\end{array}$ & $\begin{array}{l}\text { As a community of } \\
\text { praxis, we engage with } \\
\text { our activities as } \\
\text { academics in two } \\
\text { differently positioned }\end{array}$ \\
\hline
\end{tabular}




\begin{tabular}{|l|l|}
\hline \multirow{2}{|l|}{} & $\begin{array}{l}\text { HEIs and different } \\
\text { disciplines. }\end{array}$ \\
& $\begin{array}{l}\text { The context further } \\
\text { includes our involvement } \\
\text { in PAD courses. }\end{array}$ \\
\hline
\end{tabular}

\begin{tabular}{|l|l|l|}
\hline $\begin{array}{l}\text { Critically } \\
\text { dialogical }\end{array}$ & $\begin{array}{l}\text { 'the researcher ... an } \\
\text { active instrument and } \\
\text { participant in creating } \\
\text { meaning and } \\
\text { constructing values' }\end{array}$ & $\begin{array}{l}\text { Our data is the result of a } \\
\text { multimodal engagement } \\
\text { in a community of praxis } \\
\text { that represents multiple } \\
\text { entry and exit points. }\end{array}$ \\
$\begin{array}{l}\text { 'building on each } \\
\text { other's stories, } \\
\text { gaining insight from } \\
\text { group sharing' }\end{array}$ & $\begin{array}{l}\text { Our data is always in the } \\
\text { process of becoming, as } \\
\text { we are. }\end{array}$ \\
\hline
\end{tabular}

We understand multimodality as the 'forms of representation through which students make their meaning' (Stein 2008: 1). As a collaborative community of praxis, we consider ourselves as the students in PAD courses and reflect on our activities from multiple perspectives and through the use of multimodality. The multimodal 'forms of representation' we engaged with included sculpting with clay, writing poetry, interacting (tearing, folding, extracting) with old books, developing concepts, using walking as research methodology, using free and creative writing, finger painting, and creating stories and narratives through stop animation. We engaged in these multimodal methods over an eighteen-month period and in two PAD courses, entitled Multimodal pedagogies and post-qualitative scholarship in higher education teaching and learning, and Reconfiguring scholarship: Doing academic writing, publishing and reviewing differently.

Continuous weekly reading and writing sessions within a community of praxis deepened our engagement not only with text, but also with our data and the generation of new data. Our data came to be through a 'continuous process of making and unmaking' (Jackson \& Mazzei 2013: 262).

Figure 1 illustrates extracts from the multimodal process. 
Creative Meaning-Making in Higher Education Curriculum Enhancement

Figure 1: Examples of our artefacts
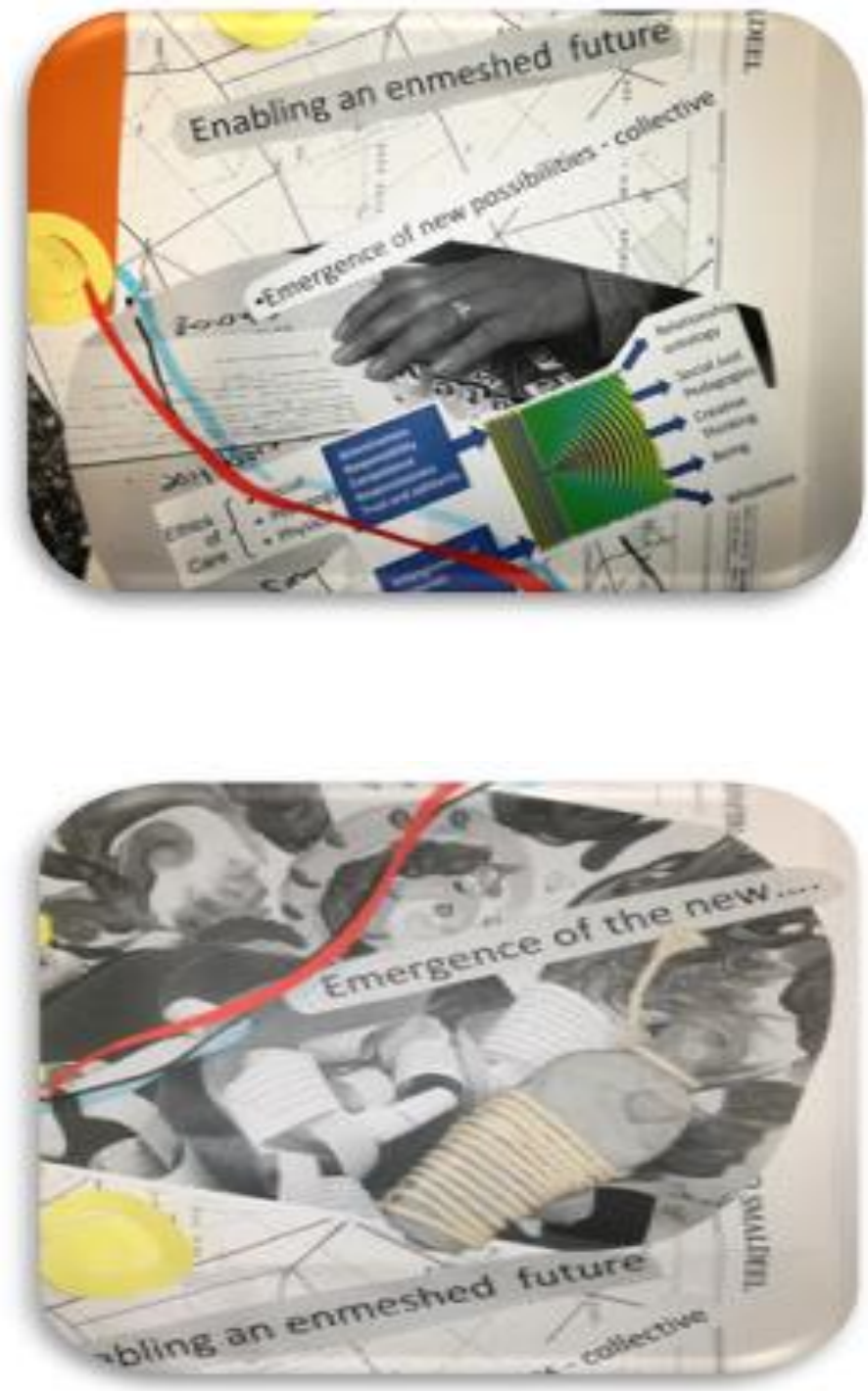


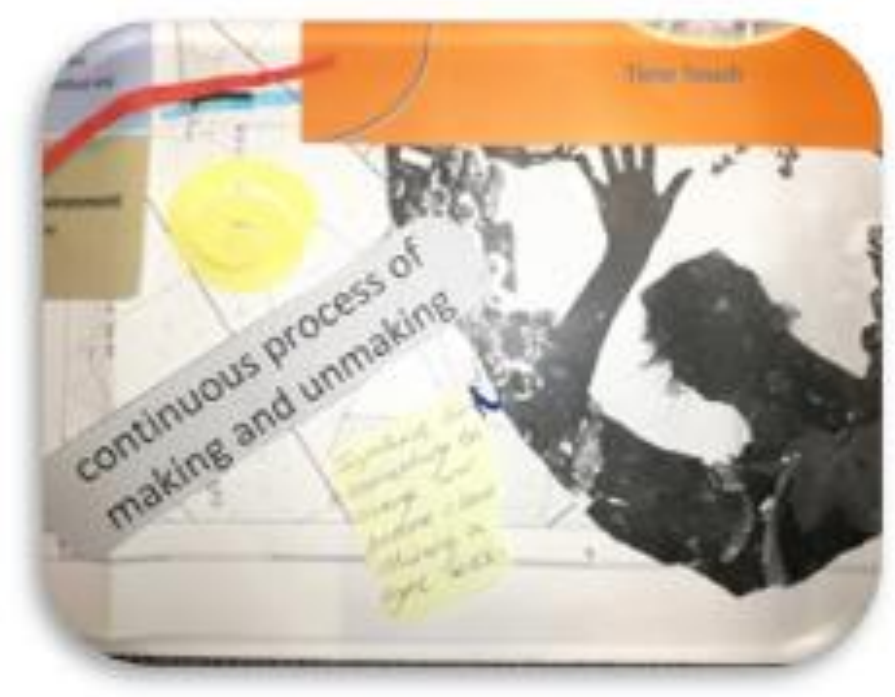

In addition, we used theory related to pedagogy to inform and deepen our analysis. We allowed our reflexivity to open up our methodology in a collaborative manner using the lenses of Touch, an Ethic of Care and Slow. In reconnecting with our data through the writing of this paper, we stepped back and once again focused on what 'glowed' for us (MacLure 2013: 661). This enabled us to focus on those things that resonated with us.

Data was drawn from two professional academic development courses presented by the Cape Higher Education Consortium (CHEC). The first layer of data consisted of voice recordings, as well as individual and collective visual and written artefacts arising from the multimodal forms of representation, as discussed above. This was followed by a collaborative process to design a book (CHEC 2018). The next step was to merge our learning experiences into a poster presentation at the 2018 conference of the Higher Education Learning and Teaching Association of South Africa.

Our data analysis and presentation thus reflect the complex and multilayered nature of the process in which we engaged. In order to think within this complex process, we used a spiral to show the entanglement, as illustrated in Figure 2 below. 


\section{Figure 2: The entangled nature of meaning-making}

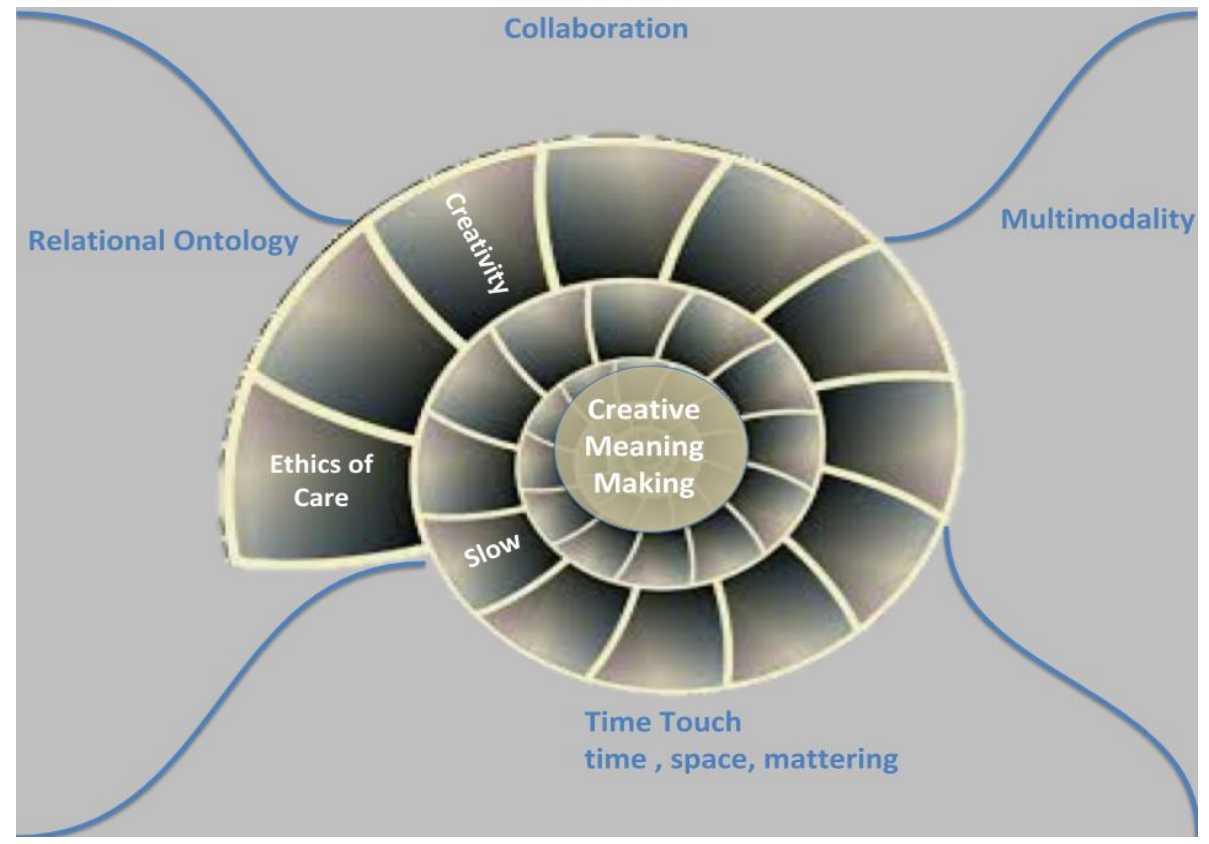

It should be noted that our engagement with methodology was an emergence in itself. It was not predetermined. We followed the suggestion of St Pierre (2018: 619): 'read, read, read and then 'do' the next thing that makes sense and keep doing the next thing and all that doing is a methodology'.

\section{Emerging Insights and Recommendations}

In this paper we describe our journey in exploring creative ways to enable different insights to emerge through our collaboration. In this space, we became aware of the shifting nature of our individual and collective understanding as we continued to hold that uncomfortable 'space of becoming' (see 4.1).

This 'space of becoming' through and with each other involved us recognising the need for shifts in our ways of thinking about our teaching and learning. For example, some of our challenges and uneasiness were: 
- Having the courage to explore and find our own voices, rather than just drawing on traditional academic language and conventions.

- Working collaboratively and tapping into the resourcefulness of the collective, rather than individualistically.

- Recognising the influences and value of engaging with multimodality to find new ways of knowing and being.

- Trusting more in the process of attentive engagement with depth of learning, rather than a superficial covering of content.

Our experience as a community of praxis created a supportive context for us to occupy this uneasy 'space of becoming'.

The following key insights into our curriculum design, content and pedagogy emerged through our processes of meaning-making and engagement with texts related to Touch, an Ethic of Care and Slow, namely:'space of (for) becoming', 'multimodal shift 'deconstructing and reconstructing entanglement', 'learning-by-modelling', 'decolonising our thinking and meaning-making'.

The structure or topography used in this section is an attempt to represent the emerging nature of our meaning-making. The sections presented in bullet points, are extracts from our weekly, collaborative reflective sessions. It depicts a natural flow of thought and our engagement with the data as it glowed and new insights emerged. Insights and recommendations about our curriculum design, content and pedagogy are elaborated upon under each of these aspects.

\section{Space of (for) Becoming}

We found 'pause' or 'stoppage' (Slow) to be an important, active part of affirming, recognising and becoming. The idea of the space in between structured activities was experienced as a fertile ground for emergent meaning-making and becoming. This created space for an authentic and deep level of engagement in order to find and create new meaning through the process:

- Space between - not focus on the activity but what lies between... 
- That space is what we need to think about what extent did the creative concept development hinge on the 'negative spaces'-that space between buildings ... design with these pauses in mind ...

- It does not mean that the invisible space is empty ...

- Importance of incubating, to process, to internally reflect and to be quiet and hold stillness. Being and not doing all the time ...

- The void assists us to be creative, being on the edge of becoming

- Our ability to create requires the stillness ...

- Not filling up [the curriculum] but letting go...

\section{Insights toward Curriculum Design, Content and Pedagogy}

Through our engagement with a Slow pedagogy, we experienced the deep value of affirming processes of collaborative meaning-making. The purpose and structure of higher education will need to shift to keep pace with change. The industrial model of education, with a prescribed timeline and curricula delivered largely in formal classroom settings, will have to transform to a more flexible model. Issues of social justice should be addressed, both in the curricular content and in the pedagogy. Recognition of the role of the student as a key agent in the meaning-making process is required. In addition, the space for collective engagement with issues of prior knowledge, values and identity needs to surface and be engaged with critically in the meaning-making process. Factors supporting and constraining student access and agency in the knowledge-generation process need to be acknowledged and worked with consciously.

One of our key insights was the need to experiment more with 'timespace', to 'pause' and not fill up the curriculum. There needs to be space for students to fill the void, reflect and add to the curriculum. Curriculum planning requires us to plan actively and attentively for pauses in order for new knowledge to be generated and for this knowledge to be deepened and internalised. There needs to be space for others to be recognised as co-creators in the knowledge-generation and meaning-making process. Pause requires a focus on process and deepening learning, rather than a superficial covering of content and outcomes. 


\section{A Multimodal Shift}

Through our collaborative engagement, using different modalities to make meaning, we experienced a shift in our thinking about what counts as knowledge, and who and what are recognised in the meaning-making process:

- Part of the discomfort is that linear did not work for us ...

- Vulnerable ...

- Move on ...

- We are bending away from the norm and the norm is not shifting $\cdots$

- Shifting, entangled and fluid ...

- The challenges of occupying space outside the academic norm.

- Creativity sits in this space of the unknown and unchartered and multimodality holds this space of allowing to be.

- Creativity asks of us to let go ... let the new emerge ...

- The discomfort of multimodality pushed me over the threshold to explore new things...

\section{Insights Toward Curriculum Design, Content and Pedagogies}

Engagement with multimodality served to heighten our awareness of the intra and interrelationships and potential for new forms of meaning-making. It required us to view, in a more complex, interrelated and sensitive way, how we experience our world and generate new knowledge. This has had an impact on our pedagogy and where we see ourselves, our students and the shifts in individual conceptions of Eurocentric ideals. Furthermore, technological change has also had an impact on our concept of what it means to be human and how we encompass this in our pedagogy with curriculum imperatives that lie in the tangible realms and in cyberspace.

We are in the process of exploring, experimenting and testing ways in which to transform our teaching. Not being afraid to experiment and venturing out into an unknown world are elements that we should instil in our curricula. We need to cultivate life-long learners who will be able to function and succeed in an uncertain and changing world. 


\section{Deconstructing and Reconstructing Entanglements}

We became aware of the centrality of entanglement between ourselves and our world through interplay between time-touch-voice-wonder-spacemattering. This creative and generative process gave rise to becoming through one another, and of everything being fluid, with the past and the future in the present:

- The continuity and texture that time-space-mattering brings ...

- Being in touch - a form of realignment, redefining and rediscovery and expanding the self ...

- Touching, reaching out (our checking-in sessions), opening up, allowing in and out ... enriching ... touching is a way of letting go $\ldots$

- Transport the learning to a different space-time to unlock creativity. Creativity does not sit in the everyday or the mundane ...

- The process of making and unmaking is pulsating like a heartbeat ... it never stops ...

- Touch-time pays attention to process, to the unfolding and refolding of meaning-making through multiple opportunities ...

- The link between touch and voice and touch as voice, for babies touch is voice. A way of being felt and heard ...

The importance of recognising that the process of becoming with and through each other created a situation in which meaning is continuously on the move and fluid. The activity of RE- becomes essential in RE-reading, RE-thinking, RE-positioning, RE-turning.

MacLure's (2013: 229) insights when considering 'wonder' resonate: Wonder is 'relational'. It is not clear where it originates and to whom it belongs. It seems to be 'out there', emanating from a particular object, image, or fragment of text; but it is also 'in' the person that is affected.

We have experienced 'wonder' numerous times in our collaborative endeavours and have come to rely on it to develop new insights:

- Again ... again ... you need something to hold and re-fold back use one article as opposed to many... 
- The voice changes with time-touch, your voice and your arguments change and Slow allows you to extract this voice and nurture the changes and sit with them...

- Re-fold, relook and re-engage ...

\section{Insights toward Curriculum Design, Content and Pedagogies}

Making space for the deconstruction and reconstruction of ideas through the process of engaging with multimodality helped to enhance creativity and new and different ways of knowing our worlds, or new ways of being in the world. We implemented multimodality in our curricula and explored its ability to allow expression through different mediums that give students a voice. In a caring community we did not position things as good or bad, but acknowledged different ways of knowing.

\section{Learning-by-Modelling}

By engaging with our own professional development, opportunities were created to deepen our curricula and learning experiences through the appreciation of Touch, an Ethic of Care and Slow:

- The voice changes with time-touch, your voice and your argument shift and Slow allows you to extract and nurture this voice ...

- What enabled the emergence of the new: Touch, Ethic of Care, Slow...

- Ethic of Care increased the learning ...

- Through one's pedagogy, you can allow people to see the world through different lenses ...

- By what you model - a new way of being and seeing and mattering

- Pedagogical competence model is influenced by time-spacemattering...

- The collaborative, communal entity enabled me...

- Ethic of Care (EoC) lens enabled an awareness ... if I did not live EoC, I would not have been sensitised to think about what I did in this way... 
- Multimodality provided the scaffolding to shift the process ...

- Gave us a way to engage with complex theories...

\section{Insights Toward Curriculum Design, Content and Pedagogies}

Collaborating in a multimodal and multidisciplinary environment enabled us to create a space for applying different lenses to our practice. We discovered a need for the different lenses to be applied within curriculum design, content and pedagogy, but also the requirement for greater sensitivity towards the timing and pacing.

\section{Decolonising our Thinking and Meaning-Making}

Our experience of generating new meaning and understanding through multimodality reinforced the key role of the participants in the meaningmaking and knowledge-construction process. One of the key insights we had was how engagement in collaborative, multimodal processes put the agents (students) at the centre of the meaning-making process in co-constructing knowledge and legitimising different forms of knowing. There was thus no 'silencing of other knowledge and way of creating knowledge' (Motta 2013: 97). There also was an acknowledgement of the importance of surfacing indigenous knowledge, affirming our lived experience in Africa, and grappling with our African identity:

- It must be hard for our students to have this instrumentalist notion of this is what we need to learn and they have no agency in the whole process. We give then [students] the rules, assignments, rubrics, etc. We are not touching their humanity ...

- Let students engage with process ... we as students were selecting the focus we were interested in ... and built the relevant theory into our own practice...

- We are transformed by creativity and translating this transformation to our classroom...

- Being uncomfortable is transformational ... intense discomfort allows something new...

- Being in community holds us up and counters the discomfort...

- We cannot go back ... 
The power of co-creation and participating in knowledge construction and generation is undeniable. Heleta (2016: 2) argues that the 'colonial and apartheid curriculum in South Africa has promoted white supremacy and dominance, as well as stereotyping of Africa', and that the current curriculum still reflects colonial and apartheid worldviews. Through our engagement in the process of co-constructing knowledge, we gained insight into how the curriculum content and process could be opened up and transformed. Collaborative engagement in the active generation of new knowledge created space for decolonising the curriculum by drawing on and recognising multiple sources and processes of knowledge generation. It also affirmed the need for a focus on Africa, and to acknowledge and generate new knowledge and insight from an African perspective.

\section{Insights Toward Curriculum Design, Content and Pedagogies}

Recognising how the material and structural conditions in our institutions both enable and constrain learning and student agency was a key insight. Heleta (2016: 7) argues that academics need to involve students in decolonising the curriculum and pedagogy through the process of creating environments that are anti-hierarchical and promote critical and collaborative engagement and critique. Our collective engagement with a multimodal, Slow pedagogy informed by a Political Ethic of Care and Touch enabled us to reclaim the space to create and recreate knowledge that was both critical and creative. Motta (2013: 88) argues for the need to reclaim these spaces as 'a critical act of opening possibility through developing pedagogies (as method and content) with students'. We need to be attentive to other's lived experiences within a particular environment, but furthermore need to become conscious of our own existence and identity as Africans and co-inhabitants of this planet. Decolonisation implies being the other. Exploring these spaces and identities raised new insights and challenged us to reflect on our current practice as lecturers preparing students for the $21^{\text {st }}$ Century and beyond.

\section{Conclusion}

This paper has shown how our thinking shifted as new pedagogical possibilities were imagined and enacted. It highlights the shifts we made in 
our thinking about our own teaching and learning practices as a result of our participation in professional academic development and continued engagement in our community of praxis. It demonstrates how the experience of collectively and Slowly engaging with related theory (lenses) and multimodal pedagogy enabled us to think in new ways about our curriculum content, design and pedagogy. Our experience may hold lessons for academics engaging with the call to decolonise the curriculum.

We recommend a 'space of (for) becoming' in curricula to create the necessary space and time for students to reflect and deepen their learning, by planning for pauses so that knowledge can deepen and be internalised; and pauses to allow the process to unfold as opposed to an overreliance on the outcome in order to allow for shifts in learning.

The value of 'deconstructing and reconstructing entanglement' via the implementation of multimodality provided different ways to explore concepts and suspend judgement. We discovered a need for the different lenses to be applied within curriculum design, but also the requirement for greater sensitivity towards the timing and pacing of what students are expected to master.

Our collaborative engagement in the active generation of new knowledge created the space for us to deconstruct our own judgement and allow for creative meaning-making. This experience opened up generative spaces for us to think in new and creative ways about our own teaching and curriculum design.

\section{Disclosure statement}

No potential conflict of interest was reported by the authors.

\section{References}

Barad, K. 2012. On Touching - The Inhuman that therefore I Am. Differences 23,3: 206 - 223. https://doi.org/10.1215/10407391-1892943

Bozalek, V. 2017. Slow Scholarship in Writing Retreats: A Diffractive. South African Journal of Higher Education 31,2: 40 - 57.

https://doi.org/10.20853/31-2-1344

Bozalek, V. \& M. Zembylas 2017. Towards a Response-Able Pedagogy Across Higher Education Institutions in Post-Apartheid South Africa: An 
Belinda Verster, Karen Collett \& Carolien van den Berg

Ethico-Political Analysis. Education as Change 21,2: 62 - 85.

https://doi.org/10.17159/1947-9417/2017/2017

Burke, P.J. 2018. Re/imagining Widening Participation: A Praxis-based

Framework. International Studies in Widening Participation 5,1: 10 - 20.

Chang, H., F.W. Ngunjiri \& K.A. Hernandez 2013. Collaborative Autoethnography. Walnut Creek, CA: Left Coast Press.

CHEC 2018. Reconfiguring Scholarship: Doing Academic Writing,

Publishing and Reviewing Differently. Unpublished.

Collett, K.S., C. van den Berg, B. Verster \& V. Bozalek 2018. Incubating a

Slow Pedagogy in Professional Academic Development: An Ethics of

Care Perspective. South African Journal of Higher Education 32,6: 117

- 136. https://doi.org/10.20853/32-6-2755

Deleuze, G. \& F. Guattari 1988. A Thousand Plateaus: Capitalism and

Schizophrenia. London: Bloomsbury Publishing.

Dhunpath, R. \& N. Amin 2019. Alternation 2019 Special Edition: Call for

Submissions. Durban: UKZN Teaching \& Learning Office, University of

KwaZulu-Natal.

Gergen, K.J. \& M.M. Gergen 1991. Toward Reflexive Methodologies. In

Steier, F. (ed.): Research and Reflexivity. (Inquiries in Social

Construction Series.) Thousand Oaks, CA: Sage Publications.

Heleta, S. 2016. Decolonisation of Higher Education: Dismantling Epistemic

Violence and Eurocentrism in South Africa. Transformation in Higher

Education 1,1: 1 - 8 .

https://doi.org/10.4102/the.v1i1.9

Jackson, A.Y. \& L.A. Mazzei 2013. Plugging One Text into Another:

Thinking with Theory in Qualitative Research. Qualitative Inquiry 19,4:

261 - 271. https://doi.org/10.1177/1077800412471510

Jamal, T. \& D. Getz 1995. Collaboration Theory and Community Tourism

Planning. Annals of Tourism Research 22,1: 186 - 204.

https://doi.org/10.1016/0160-7383(94)00067-3

Kemmis, S., H.L. Heikkinen, G. Fransson, J. Aspfors \& C. Edwards-Groves 2014. Mentoring of New Teachers as a Contested Practice: Supervision, Support and Collaborative Self-Development. Teaching and Teacher Education 43: 154 - 164. https://doi.org/10.1016/j.tate.2014.07.001

MacLure, M. 2013. The Wonder of Data. Cultural Studies $\leftrightarrow$ Critical Methodologies 13,4: 228 - 232.

https://doi.org/10.1177/1532708613487863 
Motta, S.C. 2013. Teaching Global and Social Justice as Transgressive Spaces of Possibility. Antipode 45,1: 80 - 100. Available at:

http://dx.doi.org/10.1111/j.1467-8330. 2012.00995

(Accessed on 14 June 2019.)

https://doi.org/10.1111/j.1467-8330.2012.00995.x

Pedler, M. 2012. Reflexive Methodology: New Vistas for Qualitative Research. Action Learning: Research and Practice 9,1: 83 - 87.

https://doi.org/10.1080/14767333.2012.656893

Tronto, J.C. 2013. Caring Democracy: Markets, Equality, and Justice. New York: New York University Press.

Schatzki, T. 2010. Materiality and Social Life. Nature and Culture 5,2: 123 149.

https://doi.org/10.3167/nc.2010.050202

Shaw, P., B. Cole \& J. Russell 2013. Determining Our Own Tempos: Exploring Slow Pedagogy, Curriculum, Assessment and Professional Development. To Improve the Academy 32: 319 - 334. https://doi.org/10.1002/j.2334-4822.2013.tb00713.x

Stein, P. 2008. Multimodal Pedagogies in Diverse Classrooms: Representation, Rights and Resources. London: Routledge. https://doi.org/10.4324/9780203935804

St. Pierre, E.A. 2018. Writing Post Qualitative Inquiry. Qualitative Inquiry 24,9: 603 - 608 . https://doi.org/10.1177/1077800417734567

Van Den Berg, C., B. Verster \& K.S. Collett 2018. Flipped Out in the Blended Classroom, the Good, the Bad and the Ugly: When Academics Become Students. South African Journal of Higher Education 32,6: 440 - 459. https://doi.org/10.20853/32-6-2984

Ulmer, J.B. 2018. Composing Techniques: Choreographing a Postqualitative Writing Practice. Qualitative Inquiry 24,9: 728 - 736.

https://doi.org/10.1177/1077800417732091

Belinda Verster

Urban Planning Cape Peninsula University of Technology

Cape Town versterb@cput.ac.za 
Belinda Verster, Karen Collett \& Carolien van den Berg

Karen Collett

Educational Leadership University of the Western Cape

Cape Town

kcollett@uwc.ac.za

Carolien Van Den Berg Information Systems University of the Western Cape

Cape Town cvandenberg@uwc.ac.za 